\section{Inhibition of Transcription Elongation by the VHL Tumor Suppressor Protein}

\author{
D. Roxanne Duan, ${ }^{\star}$ Arnim Pause, ${ }^{*}$ Wilson H. Burgess, \\ Teijiro Aso, David Y. T. Chen, Karla P. Garrett, \\ Ronald C. Conaway, Joan W. Conaway, W. Marston Linehan, \\ Richard D. Klausner†
}

Germline mutations in the von Hippel-Lindau tumor suppressor gene (VHL) predispose individuals to a variety of tumors, including renal carcinoma, hemangioblastoma of the central nervous system, and pheochromocytoma. Here, a cellular transcription factor, Elongin (SIII), is identified as a functional target of the VHL protein. Elongin (SIII) is a heterotrimer consisting of a transcriptionally active subunit $(A)$ and two regulatory subunits ( $B$ and $C$ ) that activate transcription elongation by RNA polymerase II. The VHL protein was shown to bind tightly and specifically to the Elongin $B$ and $C$ subunits and to inhibit Elongin (SIII) transcriptional activity in vitro. These findings reveal a potentially important transcriptional regulatory network in which the VHL protein may play a key role.
The identification of tumor suppressor disposition to cancer has taken center stage in our attempts to understand human carcinogenesis $(1,2)$. Germline mutations in these genes are responsible for a number of inherited cancer syndromes, and somatic mutations have been found in most, if not all, sporadic cancers. In addition to their great potential as diagnostic and prognostic tools, tumor suppressor genes can offer valuinvolved in the control of the cell cycle, pects of carcinogenesis.

The VHL gene is mutated in families with von Hippel-Lindau disease (3-5), a rare disorder (incidence $\approx 1$ in 36,000) that of cancers, including clear-cell renal carcinoma, hemangioblastoma, and pheochromocytoma [(4) and references therein]. Renal tumors from VHL patients carry germline VHL mutations and show selective loss of the wild-type VHL allele inherited from the unaffected parent $(5,6)$. As predicted by Knudson's two-hit hypothesis for tumor suppressor gene inactivation, the majority of

R. Duan, D Y.T. Chen, and W. M. Linehan are in the Cancer Institute, National Institutes of Health, Bethesda, MD 20892, USA. A. Pause and R. D. Klausner are in the Cell Biology and Metabolism Branch, National Institute of Child Health and Human Development, National Institutes of Health, Bethesda, MD 20892, USA. W. H. Burgess is in the Department of Molecular Biology, Holland Laboratory, Rockville, MD 20855, USA. T. Aso, K. P. Garrett, R. C. Conaway, and J. W. Conaway are in the Program in Molecular Biology, Oklahoma Medical Research Foundation, Oklahoma City, OK 73104, USA

* These authors contributed equally to this work.

†To whom correspondence should be addressed. genes whose loss of function results in preable insight into the fundamental pathways genome stability, cell death, and other aspredisposes affected individuals to a variety Urologic Oncology Section, Surgery Branch, National patients with sporadic clear-cell renal carcinoma show functional loss of both alleles of the VHL locus in their tumors $(7,8)$.

The human VHL gene encodes a protein of 213 amino acids with no significant homology to known proteins (3). The rat homolog is $88 \%$ identical to human VHL, but lacks an acidic pentapeptide motif that is repeated eight times in the $\mathrm{NH}_{2}$-terminus of the human protein (9). In previous studies, we found that the human and rat VHL proteins formed oligomeric complexes with several unidentified proteins in cultured mammalian cells (9). One of these complexes, a heterotrimer consisting of $\mathrm{VHL}$ and two proteins of $9 \mathrm{kD}$ and $16 \mathrm{kD}$, did not form when the VHL protein contained cer- tain missense mutations found in human cancers (9). This observation suggested that the $9-\mathrm{kD}$ and $16-\mathrm{kD}$ proteins were potentially involved in the normal tumor suppressor function of VHL (9), and we therefore set out to identify these proteins.

A stably transfected HeLa cell line expressing a rat full-length VHL that had been epitope-tagged with Flag (DYKDDDDK) (10) was used for immunoaffinity purification of VHL and its associated proteins (11). After separation by SDS-polyacrylamide gel electrophoresis (PAGE), the bands corresponding to the associated proteins that we previously denoted p16 and p9 (Fig. 1A) were digested with the protease Lys C. Eluted peptides were purified by reversed-phase high-performance liquid chromatography (HPLC) and sequenced by Edman degradation. The band labeled VHL was also iden- 10 tified by sequence analysis, which confirmed 5 the predicted start codon, amino acid 1 of the rodent VHL open reading frame $(9,12)$.

As revealed by a database search, a peptide sequence derived from $\mathrm{p} 9$ demonstrated a 19 out of 20 amino acid match to a 응 sequence present in Elongin C, a 112-amino acid protein that was originally purified $\overline{0}$ as a subunit of the heterotrimeric transcrip- 온 tion elongation factor Elongin (SIII) (13). Elongin (SIII) activates transcription elongation of RNA polymerase II (Pol II), the major polymerase for messenger RNA synthesis. As determined by in vitro assays, Elongin (SIII) suppresses the transient of pausing of Pol II that occurs at many sites throughout transcription units $(14,15)$. Elongin (SIII) also contains a $110-\mathrm{kD}$ subunit (A) and an $18-\mathrm{kD}$ subunit (B) $(14,16$, 17). Our previous immunoprecipitation studies had revealed coassociation of VHL with $\mathrm{p} 9$ and p16, but not with a 110-kD protein (9). Furthermore, the migration of
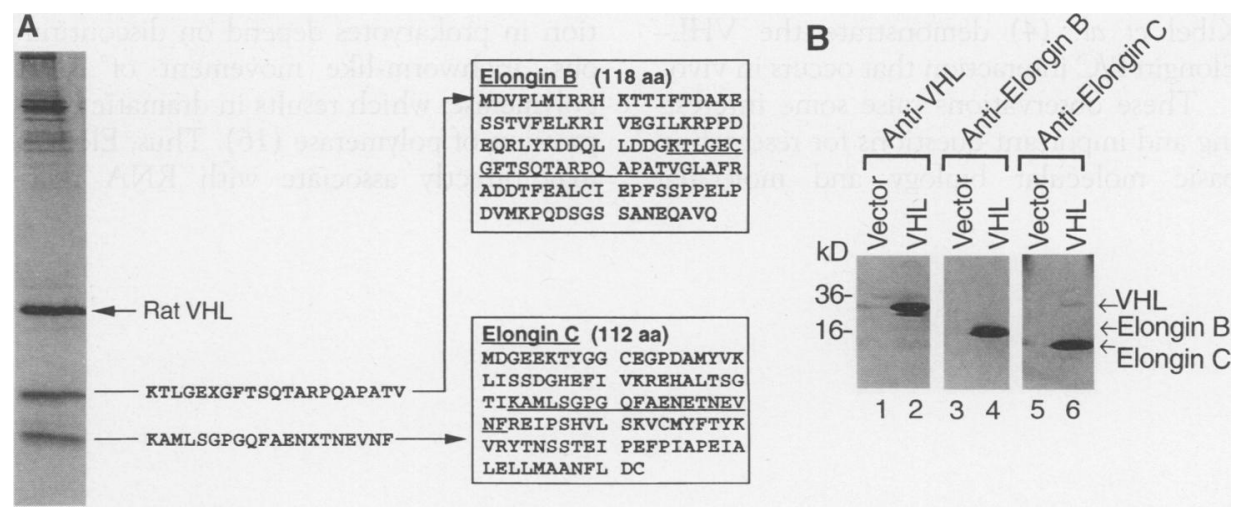

Fig. 1. Purification and sequencing of $p 16$ and p9. Extracts from HeLa cells stably transfected with pSX-R8F (rat VHL tagged with a Flag epitope at the $\mathrm{COOH}$-terminus) were immunoprecipitated with anti-Flag, washed, and eluted with glycine-HCl. (A) The eluate was analyzed by $15 \%$ SDS-PAGE and stained with Coomassie brilliant blue. Peptide sequences of VHL-associated p16 and p9 are shown and underlined in the Elongin B (GenBank accession number L42858) and Elongin C (GenBank accession number L29259) sequences (10). (B) The anti-Flag resin eluates from vector-transfected cells (lanes 1, 3, and 5) or from rat VHL-transfected cells (lanes 2, 4, and 6) were analyzed on immunoblots developed with anti-Flag (to detect $\mathrm{VHL}$ ), anti-Elongin $\mathrm{B}$, or anti-Elongin $\mathrm{C}$. 
the VHL-p9-p16 complexes on sucrose gradients was consistent with a size of $\sim 40$ to $50 \mathrm{kD}$ (9). We tested whether p16 was another Elongin subunit by protein sequence analysis, and discovered that a pep- tide from p16 showed a 20 out of 21 amino acid match to a sequence in Elongin B (17) (Fig. 1A).

We verified the identity of the VHLassociated p9 and p16 as Elongin B and C,
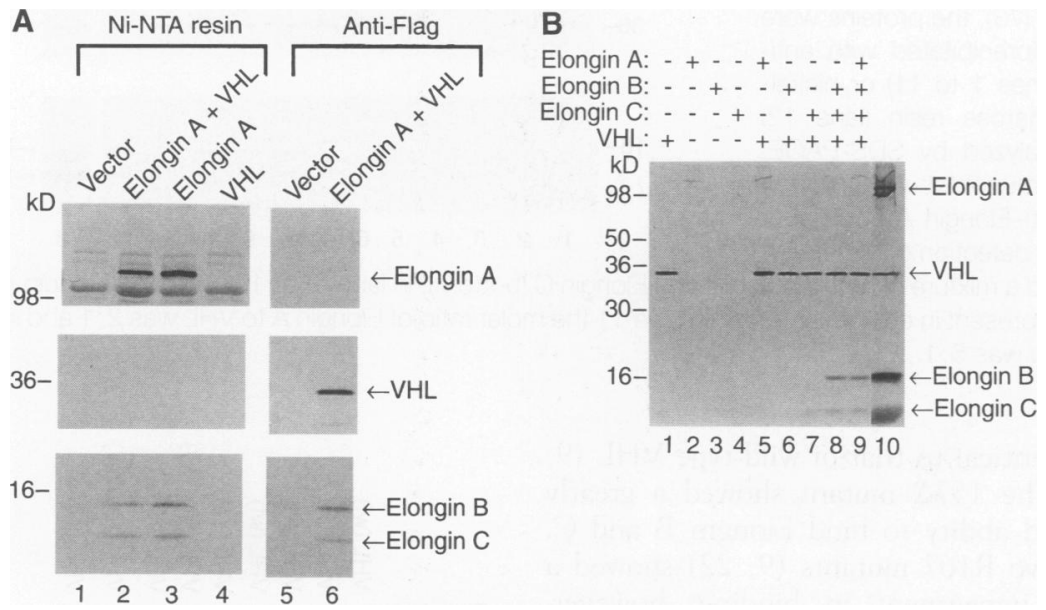

Fig. 2. Detection of a complex containing VHL and Elongin $B$ and C. (A) COS-7 cells transfected with pSVL-His-p110 (Elongin A), pSX-Fg7 (human VHL tagged with Flag), or both plasmids were lysed, and proteins were precipitated with nickel-NTA agarose resin, which binds to the His tag (lanes 1 to 4). The supernatants of the nickel-NTA agarose resin precipitates were immunoprecipitated with anti-Flag (lanes 5 and 6). The immunoblot was developed with rabbit polyclonal anti-Elongin A (top), anti-Flag (middle), or a mixture of anti-Elongin $\mathrm{B}$ and anti-Elongin $\mathrm{C}$ (bottom). (B) The CDNAs encoding Flag-VHL, His-Elongin $A$, and Elongin $B$ and $C$ were expressed in a reticulocyte-coupled transcription-translation system in the presence of ${ }^{35} \mathrm{~S}$-methionine. The translation products were immunoprecipitated with anti-Flag, fractionated by $15 \%$ SDS-PAGE, and detected by autoradiography. Lane 10 contains $1 / 2$ oth of the reaction mixture used for immunoprecipitation in lanes 1 to 9 .
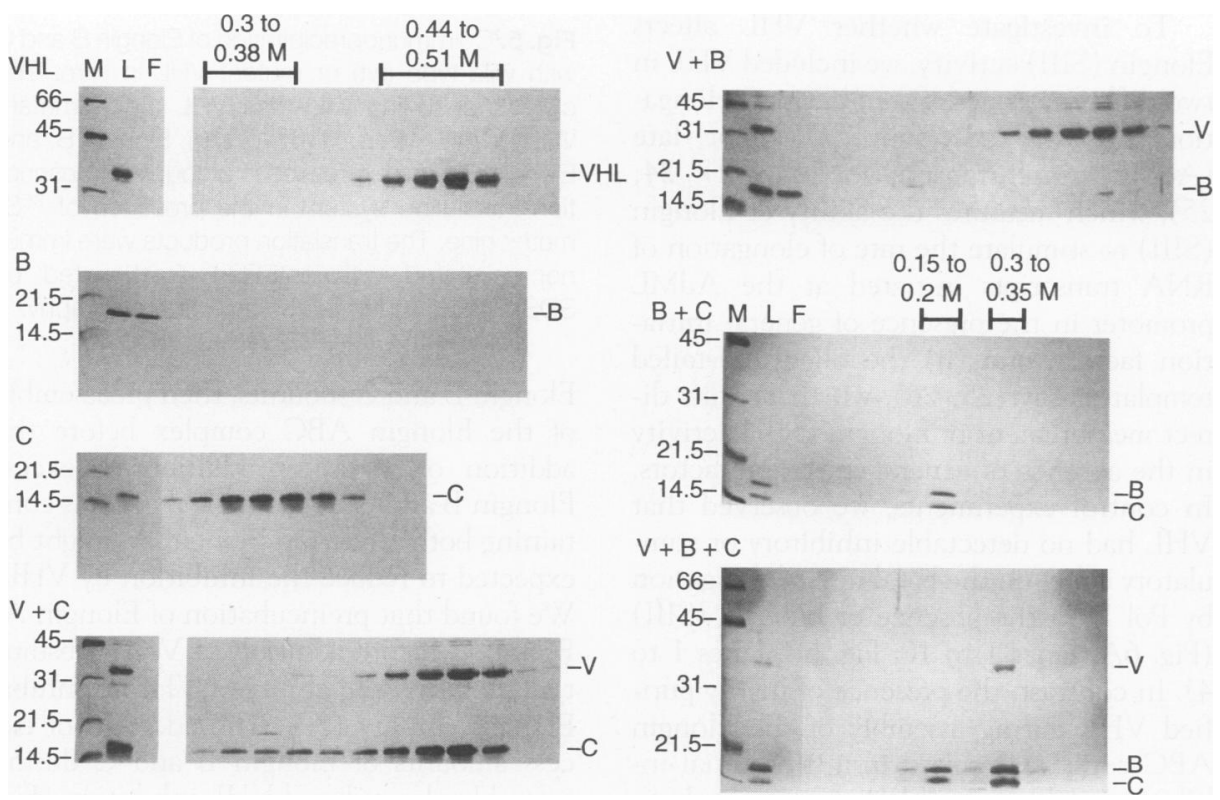

Fig. 3. HPLC purification of complexes containing VHL and Elongin $B$ and C. Recombinant His-VHL and Elongin $\mathrm{B}$ and $\mathrm{C}$ were prepared from bacterial inclusion bodies and purified by nickel chromatography (13). VHL was renatured in the presence of various combinations of Elongin $B$ and $C(13,14,17)$ in mixtures containing $60 \mu \mathrm{g}$ of His-VHL, $30 \mu \mathrm{g}$ of His-Elongin B (17), and $30 \mu \mathrm{g}$ of His-Elongin C (13). After dialysis, the renatured proteins were applied to a TSK DEAE-NPR column ( $35 \mathrm{~mm}$ by $4.6 \mathrm{~mm}$; HewlettPackard) equilibrated in $40 \mathrm{mM}$ tris- $\mathrm{HCl}$ (pH 7.9), $0.1 \mathrm{mM}$ EDTA, $1 \mathrm{mM} \mathrm{DTT}, 10 \%(\mathrm{v} / \mathrm{v})$ glycerol, and 60 $\mathrm{mM} \mathrm{KCl}$. The column was eluted at $0.3 \mathrm{ml} / \mathrm{min}$ at $8^{\circ} \mathrm{C}$ with a $3-\mathrm{ml}$ gradient from $0.06 \mathrm{M}$ to $0.6 \mathrm{M} \mathrm{KCl}$ in the same buffer. Samples of each column fraction were analyzed by $12 \%$ SDS-PAGE, and the proteins were visualized by silver staining. The apparent molecular masses of protein standards are indicated on the left. V, VHL; B, Elongin B; C, Elongin C; M, marker; L, column load; F, column flowthrough.

respectively, by immunoblot analysis with antibodies directed against Elongin $\mathrm{B}$ or $\mathrm{C}$ (Fig. 1B). These antibodies recognize their antigen targets on immunoblots but do not directly immunoprecipitate them. The question of whether Elongin A stably binds to VHL was assessed by cotransfection of COS-7 cells with vectors encoding either human VHL tagged with Flag at the $\mathrm{NH}_{2}$ terminus (Flag-VHL) or Elongin A tagged with histidine (His-Elongin A) (18). Protein complexes were purified with antibody to Flag (anti-Flag) or with a nickel-nitrioltri-acetate (nickel-NTA) agarose resin, which binds to the His tag. The resultant complexes were resolved by SDS-PAGE and analyzed on immunoblots developed with antibodies specific for each of the four target proteins (Fig. 2A). The nickel resin purified Elongin $\mathrm{A}$ complexed to the $\mathrm{B}$ and C subunits but did not purify VHL (lane 2). Conversely, the anti-Flag purified Elongin $\mathrm{B}$ and $\mathrm{C}$ in a complex with VHL but did not purify Elongin A (lane 6).

To assess the range of interactions between these proteins, we cloned the complementary DNAs (cDNAs) encoding FlagVHL, His-Elongin A, and Elongin B and C into $\mathrm{pGEM} 3$ vectors, and examined the fate of the protein products synthesized in coupled transcription-translation systems (19). In reactions immunoprecipitated with antiFlag (Fig. 2B), we observed no coprecipitation of Elongin $\mathrm{A}$ with $\mathrm{VHL}$, whether the former was synthesized with VHL alone (lane 5) or in combination with the other subunits (lane 9). The small amount of Elongin $\mathrm{A}$ in the precipitates (lanes 5 and 9) was no greater than in control lysates containing no Flag-VHL (lane 2). There was no evidence for binding of VHL to Elongin $\mathrm{B}$ alone (lane 6), although there was some detectable binding of VHL to Elongin $\mathrm{C}$ alone (lane 7). When VHL was translated with both Elongin $\mathrm{B}$ and $\mathrm{C}$, the binding of both Elongin $\mathrm{B}$ and $\mathrm{C}$ to VHL was enhanced (lane 8 ). The ability of the His-Elongin A to form complexes in this in vitro system was examined by precipitation of the translation products with a nickelNTA agarose resin. These results precisely mirrored those obtained by anti-Flag immunoprecipitation of VHL (20). There was a small amount of assembly of Elongin A with $\mathrm{C}$ but no significant association of Elongin $B$ with $A$ in the absence of $C$. In contrast, cotranslation of all three subunits resulted in increased binding of Elongin $B$ and $C$ to Elongin A. No VHL was assembled with Elongin $A$, regardless of the presence of associated subunits (20).

We also assessed the ability of recombinant VHL, Elongin $\mathrm{B}$, and Elongin $\mathrm{C}$ to assemble (Fig. 3). The three bacterially expressed proteins were renatured alone or in various combinations, and the resultant 
complexes were analyzed by anion-exchange HPLC on TSK diethyl-amino-ethyl nonporous resin (DEAE-NPR). The individually renatured $\mathrm{VHL}$, Elongin $\mathrm{B}$, and Elongin $\mathrm{C}$ proteins exhibited distinct elution DEAE-NPR profiles. Elongin B flowed through the column at $0.06 \mathrm{M} \mathrm{KCl}$, whereas Elongin $\mathrm{C}$ and VHL bound to the column and eluted at 0.3 to $0.4 \mathrm{M} \mathrm{KCl}$ and 0.44 to $0.5 \mathrm{M} \mathrm{KCl}$, respectively. Upon renaturation and chromatography of mixtures of either VHL plus Elongin C, or VHL plus Elongin $\mathrm{B}$, a substantial fraction of Elongin C coeluted with VHL as a VHL-Elongin C complex. In contrast, very little Elongin B coeluted with VHL. Finally, upon renaturation and chromatography of a mixture of VHL and both Elongin B and C, a portion of the Elongin $\mathrm{B}$ and $\mathrm{C}$ subunits copurified as an Elongin $\mathrm{BC}$ complex that eluted from the column in a discrete peak, and nearly all of the remaining Elongin $\mathrm{B}$ and $\mathrm{C}$ coeluted with VHL as a VHL-Elongin BC complex. Thus, in three different experimental systems, we consistently observed formation of both the VHL-Elongin C and VHL-Elongin $\mathrm{BC}$ complexes, but not of the VHLElongin B complex.

The absence of complexes containing both $\mathrm{VHL}$ and Elongin A suggested that the VHL-Elongin $\mathrm{BC}$ and the Elongin $\mathrm{ABC}$ complexes were mutually exclusive and that VHL and Elongin A might compete for binding to Elongin B and C. This hypothesis was tested by analysis of the assembly of recombinant proteins that had been denatured and then renatured $(13,21)$. Complex formation was detected by immunoprecipitation with anti-Flag (Fig. 4). Equimolar input of each protein resulted in formation of VHL-Elongin BC complexes containing no Elongin A (lane 9). Input of a fivefold molar excess of Elongin A resulted in loss of the VHL-Elongin BC complexes and presumed formation of Elongin ABC complexes (lane 11). VHL has no apparent sequence similarity with Elongin B or C, but does share a stretch of 13 amino acids with Elongin A (16), and it is this region of VHL that has been implicated in the interaction with Elongin B and $\mathrm{C}(22,23)$.

We next investigated the effect of $\mathrm{VHL}$ mutations on Elongin interactions. We analyzed several of the VHL mutations that have been identified either in the germ line of patients with VHL disease or in the DNA from sporadic renal cell carcinomas $(7,8,24)$. These included three missense mutations (Y98H, R167Q, and R167W)

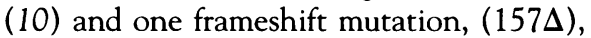
in which exon 3 is deleted. COS-7 cells transiently transfected with the appropriate cDNAs expressed wild-type levels of the VHL mutants; these proteins were not grossly misfolded, as judged by their ability to interact with cellular proteins in a man-
Fig. 4. Competition between $\mathrm{VHL}$ and Elongin $\mathrm{A}$ for binding to Elongin $\mathrm{B}$ and $\mathrm{C}$. Recombinant His-Elongin $\mathrm{A}$, His-VHLFlag, Elongin $\mathrm{B}$, and Elongin $\mathrm{C}$ were mixed in different combinations in $6 \mathrm{M}$ guanidine- $\mathrm{HCl}$ denaturing buffer. After renaturation (13), the proteins were immunoprecipitated with antiFlag (lanes 1 to 11) or nickelNTA agarose resin (lane 12) and analyzed by SDS-PAGE. The immunoblot was probed with anti-Elongin A (top), antiFlag for detection of VHL (mid-

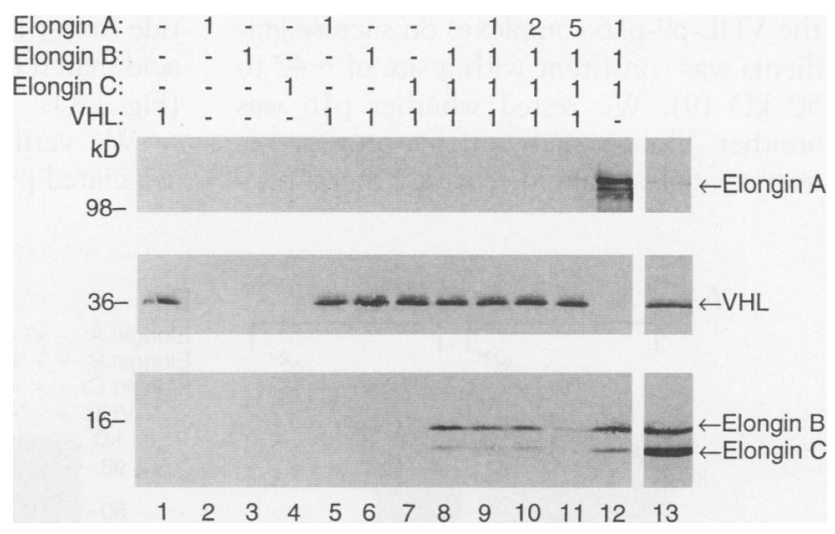
dle), and a mixture of anti-Elongin B and Elongin C (bottom). In lanes 1 to 10, VHL and Elongin A, B, and $C$ were present in equimolar ratios. In lane 11 the molar ratio of Elongin $A$ to VHL was 2:1 and in lane 12 the ratio was $5: 1$.

ner identical to that of wild-type VHL (9, 22). The $157 \Delta$ mutant showed a greatly reduced ability to bind Elongin $\mathrm{B}$ and $\mathrm{C}$. The two R167 mutants $(9,22)$ showed a slight impairment in binding; however, binding of these mutants was completely lost if the lysates contained the anionic detergent Sarkosyl $(0.2 \%)$, conditions that had no effect on the binding of wild-type VHL (20). Under either condition, the binding of the $\mathrm{Y} 98 \mathrm{H}$ mutant to Elongin $\mathrm{B}$ and $C$ was comparable to that of wild-type VHL. The effects of these mutants were also examined in the transcription-translation system (19), and similar results were observed (Fig. 5).

To investigate whether VHL affects Elongin (SIII) activity, we included VHL in two different assays of transcription elongation: (i) the adenovirus 2 major late (AdML) runoff transcription assay $(17,24$, 25 ), which measures the ability of Elongin (SIII) to stimulate the rate of elongation of RNA transcripts initiated at the AdML promoter in the presence of general initiation factors; and (ii) the oligo(dC)-tailed template assay $(25,26)$, which permits direct measurement of Elongin (SIII) activity in the absence of general initiation factors. In control experiments, we observed that VHL had no detectable inhibitory or stimulatory effect on the basal rate of elongation by Pol II in the absence of Elongin (SIII) (Fig. 6A, lanes 1 to 10; Fig. 6B, lanes 1 to $4)$. In contrast, the presence of highly purified VHL during assembly of the Elongin $A B C$ complex resulted in a substantial inhibition of Elongin (SIII) activity, in both the AdML runoff transcription assay (Fig. $6 \mathrm{~A}$, lanes 11 to 20 ) and the oligo $(\mathrm{dC})$ tailed template assay (Fig. 6B, lanes 5 to 16). The inhibitory activity copurified with VHL protein (Fig. 6C), supporting the idea that the VHL protein is the inhibitor.

If the VHL protein inhibits Elongin (SIII) activity by sequestering and thereby negatively regulating the activities of the

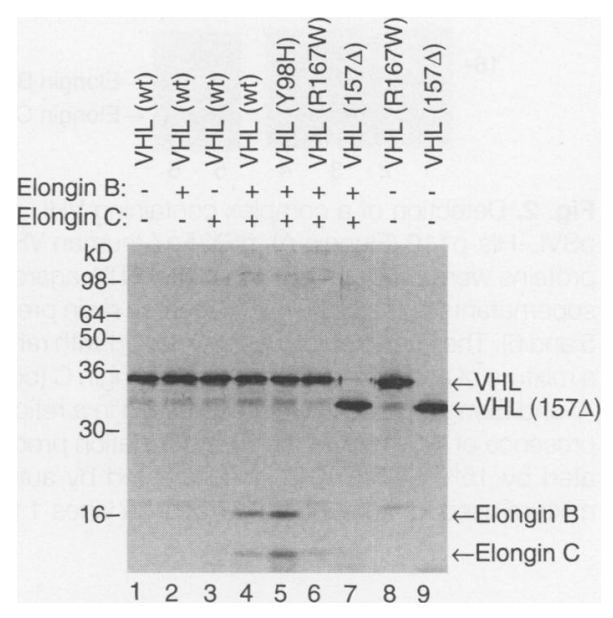

Fig. 5. Coimmunoprecipitation of Elongin $B$ and $C$ with wild-type (wt) or mutant VHL in vitro. The cDNAs encoding wild-type VHL (Fg7), mutant VHL (Y98H, 157 1 , R167W) (10), Elongin B, and Elongin $C$ were expressed in a coupled transcription-translation system in the presence of ${ }^{35} \mathrm{~S}$ methionine. The translation products were immunoprecipitated with anti-Flag, fractionated by SDS-PAGE, and detected by autoradiography.

Elongin $B$ and $C$ subunits, then preassembly of the Elongin $\mathrm{ABC}$ complex before the addition of $\mathrm{VHL}$, or addition of excess Elongin $\mathrm{B}$ and $\mathrm{C}$ to assembly reactions containing both VHL and Elongin A, might be expected to reduce the inhibition by VHL. We found that preincubation of Elongin $A$, $B$, and $C$ before addition of VHL substantially reduced the ability of VHL to inhibit Elongin activity (27). The addition of excess amounts of Elongin $B$ and $C$ during assembly also reduced VHL inhibition (Fig. $6 \mathrm{~B}$, compare lanes 9 to 12 with lanes 13 to 16). These results indicate that VHL can block Elongin (SIII) transcriptional activity in vitro and may have a similar function in vivo. It is noteworthy that VHL causes a slight but reproducible inhibition of transcriptional stimulation by Elongin $\mathrm{A}$ alone (Fig. 6B, lanes 5 to 8 ), raising the possibility that it may interact weakly with Elongin A. 
A

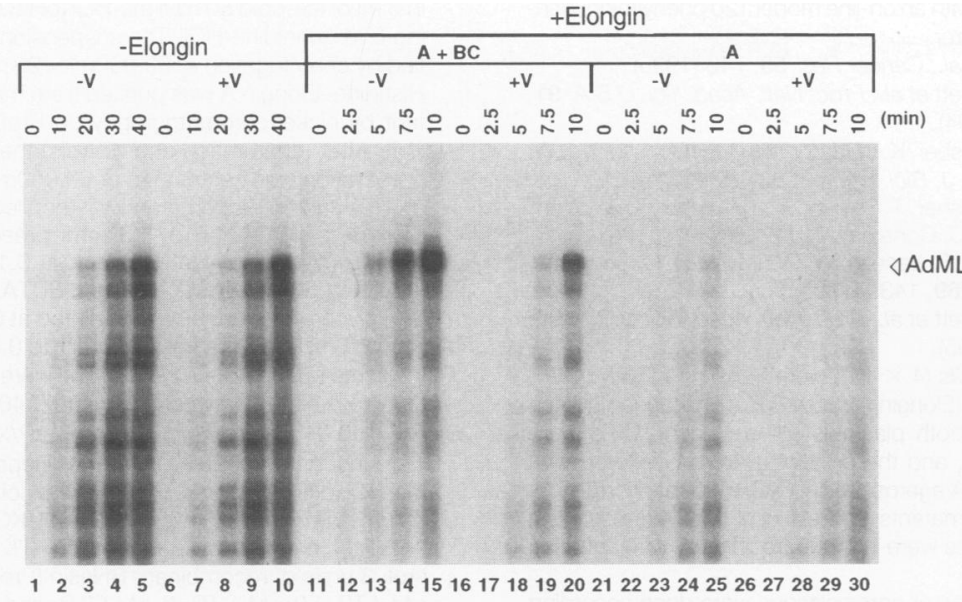

ํㅡㄹ

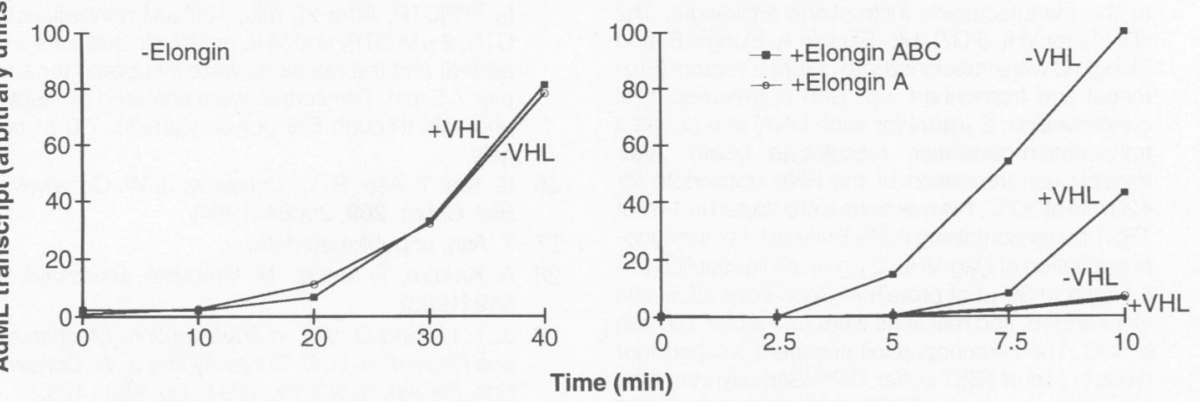

Fig. 6. Inhibition of transcription elongation in vitro by VHL. Recombinant VHL and Elongin BC were prepared as in Fig. 3. His-Elongin A was prepared from inclusion bodies (16) and purified by nickel chromatography and TSK SP-NPR HPLC (25). (A) AdML runoff transcription assays (16) were carried out for the indicated times in the absence of Elongin $\mathrm{ABC}$ (lanes 1 to 10) or in the presence of $4 \mathrm{nM}$ purified Elongin A plus $4 \mathrm{nM}$ purified Elongin $\mathrm{BC}$ complex (lanes 11 to 20), or $4 \mathrm{nM}$ purified Elongin $\mathrm{A}$ alone (lanes 21 to 30 ). Reactions marked $+\mathrm{V}$ contained $4 \mathrm{nM}$ VHL. Synthesis of full-length runoff transcripts was quantitated by Phosphorimager analysis. (B) The oligo(dC)-tailed template assays (26) contained no Elongin $\mathrm{ABC}$ (lanes 1 to 4 ), $4 \mathrm{nM}$ purified Elongin $\mathrm{A}$ (lanes 5 to 8 ), $4 \mathrm{nM}$ purified Elongin A plus $4 \mathrm{nM}$ purified Elongin BC complex (lanes 9 to 12), or $4 \mathrm{nM}$ purified Elongin A plus $36 \mathrm{nM}$ purified Elongin BC complex (lanes 13 to 16). VHL was present in reaction mixtures at $4 \mathrm{nM}$ (lanes 2, 6, 10, and 14); $12 \mathrm{nM}$ (lanes 3, 7, 11, and 15); or $36 \mathrm{nM}$ (lanes 4, 8, 12, and 16). (C) Cochromatography of VHL and Elongin (SIII) inhibitory activity. Recombinant His-VHL was prepared as in Fig. 3. Samples of each fraction from the TSK DEAE-NPR template assay (top) and analyzed by $12 \%$ SDS-PAGE and silver staining (bottom). $\alpha$-am, $\alpha$-amanitin; L, column load; F, column flowthrough; M, marker
In conclusion, we have found that overexpressed VHL can bind tightly and specifically to Elongin $\mathrm{B}$ and $\mathrm{C}$ and prevent their assembly with Elongin $\mathrm{A}$, the transcriptionally active subunit of the Elongin (SIII) complex (Fig. 7). The VHL-Elongin BC interaction is also observed with endogenous protein (23), and the correlation of at mutants with loss of Elongin BC binding activity indicates that this interaction is likely to be physiologically important in the tumor suppressor function of VHL. The mutations that do not disrupt VHL binding to Elongin $\mathrm{BC}$ may alter $\mathrm{VHL}$ interaction with other protein targets (9) that may be important to its normal function.

The inhibitory effect of VHL on transcription elongation is consistent with the hypothesis that tumor suppressor genes have negative regulatory effects on critical cellular functions. Our results raise several questions. Does VHL regulate gene expression in vivo and, if so, how? In principle, least a subset of naturally occurring VHL
VHL could regulate gene expression indirectly by controlling other processes coupled to Pol II transcription elongation, such as DNA damage recognition and repair. Alternatively, it could directly regulate the expression of specific genes by controlling the rate of transcription elongation. It is noteworthy that a growing number of eukaryotic genes are now believed to be regulated at the elongation level by mecha-
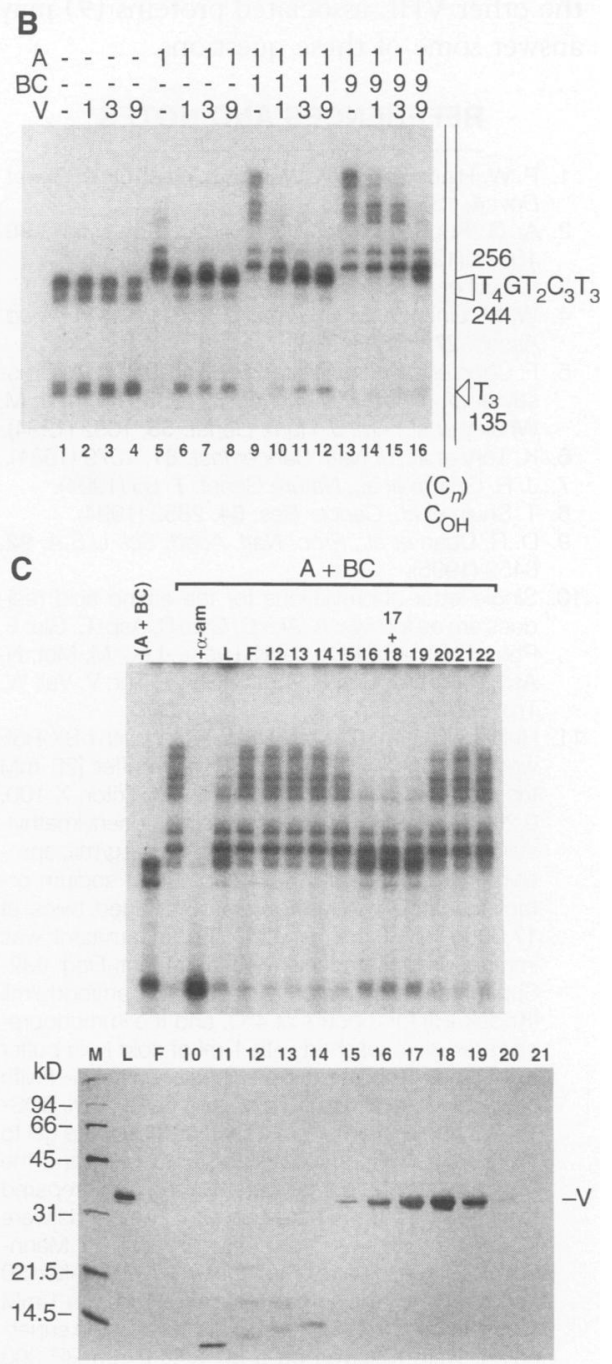

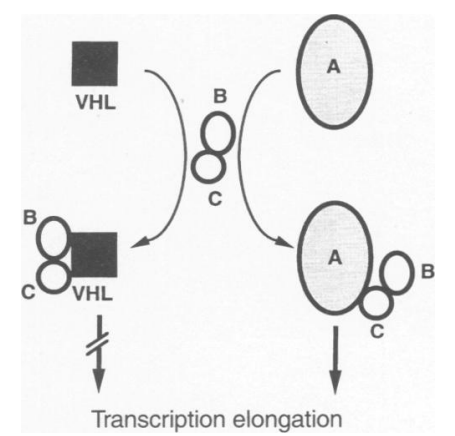

nisms such as "promoter-proximal" attenuation $(28,29)$. In addition, the recent discovery that transcriptional activators, including VP-16 and E1A, regulate transcription in part by stimulating the rate of elongation raises the possibility that transcription elongation factors may be targets for gene-specific transcriptional activators in vivo $(30,31)$. Finally, how is the function of VHL controlled? Identification of
Fig. 7. A model for the interaction between $\mathrm{VHL}$ and Elongin (SIII). Transcription elongation activity of $\mathrm{Pol} I I$ is inefficient in vitro if Elongin (SIII), composed of subunits A, B, and C, is absent. It is proposed that Elongin $A$ and $\mathrm{VHL}$ compete for binding to subunits $B$ and $C$, which positively regulate Elongin activity, to either stimulate (Elongin A) or inhibit (VHL) transcription elongation. Cells may contain two protein complexes ( $\mathrm{VHL}-$ Elongin $\mathrm{BC}$ and Elongin $A B C$ ), and the ratio of these complexes may determine the transcription elongation activity of Pol II. 
the other VHL-associated proteins (9) may answer some of these questions.

\section{REFERENCES AND NOTES}

1. P. W. Hinds and R. A. Weinberg, Curr. Opin. Genet. Dev. 4, 135 (1994).

2. A. G. Knudson, Proc. Natl. Acad. Sci. U.S.A. 90, 10914 (1993)

3. F. Latif et al., Science 260, 1317 (1993).

4. W. M. Linehan, M. I. Lerman, B. Zbar, J. Am. Med. Assoc. 273, 564 (1995).

5. F. Chen et al., Hum. Mutat. 5, 66 (1995); P. A. Crossey et al., Hum. Mol. Genet. 3, 1303 (1994); J. M Whaley et al., Am. J. Hum. Genet. 55, 1092 (1994)

6. K. Tory et al., J. Natl. Cancer Inst. 81, 1079 (1981).

7. J. R. Gnarra et al., Nature Genet. 7, 85 (1994).

8. T. Shuin et al., Cancer Res. 54, 2852 (1994)

9. D. R. Duan et al., Proc. Natl. Acad. Sci. U.S.A. 92, 6459 (1995).

10. Single-letter abbreviations for the amino acid residues are as follows: A, Ala; C, Cys; D, Asp; E, Glu; F, Phe; G, Gly; H, His; I, lle; K, Lys; L, Leu; M, Met; N, Asn; P, Pro; Q, Gln; R, Arg; S, Ser; T, Thr; V, Val; W, Trp; and $\mathrm{Y}, \mathrm{Tyr}$.

11. HeLa cells $\left(2 \times 10^{8}\right)$ stably transfected with $p S X-R 8 F$ were lysed in $15 \mathrm{ml}$ of TBST lysis buffer [20 mM tris- $\mathrm{HCl}(\mathrm{pH} 8.0), 137 \mathrm{mM} \mathrm{NaCl}, 1 \%$ Triton X-100, $0.2 \%$ Sarkosyl, $10 \%$ glycerol, $1 \mathrm{mM}$ phenylmethylsulfonyl fluoride (PMSF), leupeptin $(0.5 \mu \mathrm{g} / \mathrm{ml})$, aprotinin $(1 \mu \mathrm{g} / \mathrm{ml}), 1 \mathrm{mM} \mathrm{NaF}$, and $1 \mathrm{mM}$ sodium orthovanadate]. The lysate was centrifuged twice at $17,000 \mathrm{~g}$ for $30 \mathrm{~min}$ at $4^{\circ} \mathrm{C}$. The supernatant was immunoprecipitated with $30 \mu \mathrm{l}$ of anti-Flag (M2Sepharose conjugate; $2.9 \mathrm{mg}$ of antibody/ml) (Kodak-|BI) for 3 hours at $4^{\circ} \mathrm{C}$, and the immunoprecipitates were washed with $1 \mathrm{ml}$ of cold lysis buffer eight times. The immunoprecipitate was eluted with glycine- $\mathrm{HCl}(\mathrm{pH} 2.9)$ and analyzed on by $15 \%$ SDSPAGE. The proteins were transferred from the gel to nitrocellulose filters (Schleicher \& Schuell), and the Ponceau-stained bands were excised and prepared for in situ proteolytic digestion (32). The bands were incubated with Lys C protease (Boehringer Mannheim) at an estimated ratio of 20:1 (w/w). After 20 hours at $37^{\circ} \mathrm{C}$, the samples were treated with $1 \mathrm{mM}$ dithiothreitol (DTT) for 1 hour. Peptides in the supernatant were resolved on a $30 \times 2.1 \mathrm{~mm} R P-300$ reverse phase cartridge with the use of a model 230 microbore high-performance liquid chromatograph (Applied Biosystems). Peptides were eluted with the use of a linear gradient from $90 \% A ; 10 \% B[A=$ $0.1 \%$ trifluoroacetic acid (TFA); $B=70 \%$ acetonitrile, $0.1 \%$ TFA] to $30 \%$ A; $70 \%$ B over $40 \mathrm{~min}$. The sequences of selected peptides were determined with an Applied Biosystems Model 477A protein se- quencer with an on-line model 120 phenylthiohydantoin analyzer.

12. J. Gao et al., Cancer Res. 55, 743 (1995)

13. K. P. Garrett et al., Proc. Natl. Acad. Sci. U.S.A. 91, 5237 (1994).

14. J. N. Bradsher, K. W. Jackson, R. C. Conaway, J. W. Conaway, J. Biol. Chem. 268, 25587 (1993).

15. J. N. Bradsher, T. Siyuan, H.-J. McLaury, J. W. Conaway, R. C. Conaway, ibid., p. 25594.

16. T. Aso, W. S. Lane, J. W. Conaway, R. C. Conaway, Science 269, 1439 (1995).

17. K. P. Garrett et al., Proc. Natl. Acad. Sci. U.S.A. 92, 7172 (1995).

18. COS-7 cells $\left(4 \times 10^{6}\right)$ were transfected with pSVLHis-p110 (Elongin A), pSX-Fg7 (Flag-tagged human $\mathrm{VHL}$ ), or both plasmids (20 $\mu \mathrm{g}$ each). Cells were lysed (11), and the proteins were precipitated with nickel-NTA agarose resin (Qiagen, Chatsworth, CA). The supernatants of the nickel-NTA agarose resin precipitates were immunoprecipitated with anti-Flag $(2 \mu \mathrm{g} / \mathrm{ml})$.

19. Translations or cotranslations were done according to the manufacturer's instructions (Promega). The cDNAs for VHL (FG7), His-Elongin A, Elongin B, and Elongin $\mathrm{C}$ were subcloned into pGEM 3 vectors (Promega) and transcribed with SP6 polymerase (final concentration, $2 \mu \mathrm{g} / \mathrm{ml}$ for each DNA) in a coupled transcription-translation reticulocyte lysate. After transcription-translation of the RNA transcripts for $120 \mathrm{~min}$ at $30^{\circ} \mathrm{C}$, the reactions were diluted in $1 \mathrm{ml}$ of TBST buffer containing $0.2 \%$ Sarkosyl. For immunoprecipitation of Flag-VHL, $2 \mu \mathrm{g}$ of affinity-purified anti-Flag and $30 \mu$ l of protein A-Sepharose $(50 \% \mathrm{v} / \mathrm{v})$ were added, and reactions were rocked for $120 \mathrm{~min}$ at $4^{\circ} \mathrm{C}$. The immunoprecipitates were washed four times in $1 \mathrm{ml}$ of TBST buffer, $0.2 \%$ Sarkosyl (anti-Flag precipitates) or $1 \mathrm{ml}$ of TBST, $0.2 \%$ Sarkosyl, and 20 $\mathrm{mM}$ imidazole (Ni precipitates); analyzed by $15 \%$ SDS-PAGE, and processed for autoradiography.

20. D. R. Duan et al., unpublished data.

21. Bacterially expressed His-Elongin A, His-VHL-Flag, Elongin $\mathrm{B}$, and Elongin $\mathrm{C}$ were mixed in $6 \mathrm{M}$ guanidine- $\mathrm{HCl}$ denaturing buffer. Renaturing buffer (five volume excess to denaturing buffer) was added to the mixture. After a 90 -min incubation on ice, the renatured proteins were dialyzed against $40 \mathrm{mM}$ Hepes (pH 7.9), $100 \mathrm{mM} \mathrm{KCl}, 50 \mu \mathrm{M} \mathrm{ZnCl}$, and $10 \%$ glycerol. The dialyzed mixtures were diluted $1: 8$ with Triton X-100 lysis buffer containing $0.2 \%$ Sarkosyl and immunoprecipitated with anti-Flag or nickelNTA agarose. The precipitates were washed with lysis buffer and analyzed on a 9 to $15 \%$ SDS-polyacrylamide step gel.

22. D. Y. T. Chen and R. D. Klausner, unpublished results

23. A. Kibel, O. lliopoulos, J. A. DeCaprio, W. G. Kaelin Jr., Science 269, 1444 (1995).

24. Inclusion bodies were solubilized by resuspension in $5 \mathrm{ml}$ of ice-cold $50 \mathrm{mM}$ tris- $\mathrm{HCl}(\mathrm{pH} 8.0)$ containing $6 \mathrm{M}$ guanidine- $\mathrm{HCl}$. The suspension was clarified by centrifugation at $50,000 \mathrm{~g}$ for $20 \mathrm{~min}$ at $4^{\circ} \mathrm{C}$. Histidine-Elongin A was purified from the supernatant by nickel chromatography on ProBond resin (16). After renaturation and dialysis, the Elongin A preparation was centrifuged at $60,000 \mathrm{~g}$ for $20 \mathrm{~min}$ at $4^{\circ} \mathrm{C}$, and the supernatant was applied to a TSK SP-NPR column ( 4.6 by $35 \mathrm{~mm}$ ) preequilibrated with $40 \mathrm{mM}$ Hepes- $\mathrm{NaOH}(\mathrm{pH} 7.9), 0.1 \mathrm{M} \mathrm{KCl}, 1$ $\mathrm{mM}$ DTT, $50 \mu \mathrm{M} \mathrm{ZnSO}{ }_{4}, 0.1 \mathrm{mM}$ EDTA, and $10 \%$ (v/v) glycerol. The column was eluted at $0.6 \mathrm{ml} / \mathrm{min}$ with a 9-ml linear gradient from 0.1 to $0.8 \mathrm{M} \mathrm{KCl}$ in the same buffer. Fractions of $0.3 \mathrm{ml}$ were collected. Elongin A elutes between 0.35 and $0.40 \mathrm{M} \mathrm{KCl}$.

25. Pol II (0.01 unit) and pCpGR220S/P/X (100 ng) were incubated at $28^{\circ} \mathrm{C}$ in $20 \mathrm{mM}$ Hepes, $20 \mathrm{mM}$ tris- $\mathrm{HCl}(\mathrm{pH} 7.9), 2 \%(\mathrm{w} / \mathrm{v})$ polyvinyl alcohol, bovine serum albumin $(0.5 \mathrm{mg} / \mathrm{ml}) 60 \mathrm{mM} \mathrm{KCl}, 50 \mathrm{mM}$ $\mathrm{ZnSO}_{4}, 7 \mathrm{mM} \mathrm{MgCl}_{2}, 0.2 \mathrm{mM}$ DTT, 3\% (v/v) glycerol, 3 units of recombinant RNasin (Promega), 50 $\mu \mathrm{M}$ ATP, $50 \mu \mathrm{M}$ GTP, $2 \mu \mathrm{M}$ CTP, and $10 \mu \mathrm{Ci}$ of $\left[\alpha\right.$ - $\left.{ }^{32} \mathrm{P}\right] \mathrm{CTP}$. After $25 \mathrm{~min}, 100 \mu \mathrm{M}$ nonradioactive CTP, $2 \mu \mathrm{MUTP}$, and VHL or Elongin subunits were added, and the reactions were incubated for a further $7.5 \mathrm{~min}$. Transcripts were analyzed by electrophoresis through $6 \%$ polyacrylamide, $7.0 \mathrm{M}$ urea gels.

26. S. Tan, T. Aso, R. C. Conaway, J. W. Conaway, J. Biol. Chem. 269, 25684 (1994).

27. T. Aso, unpublished data.

28. A. Krumm, T. Meulia, M. Groudine, Bioessays 16, 659 (1993)

29. J. T. Lis and C. Wu, in Transcription: Mechanisms and Regulation, R. C. Conaway and J. W. Conaway, Eds. (Raven, New York, 1994), pp. 459-475.

30. K. Yankulow, J. Blau, T. Purton, S. Roberts, D. L. Bentley, Cell 77, 749 (1994)

31. A. Krumm, L. B. Hickey, M. Groudine, Genes Dev. 9, 559 (1995)

32. R. H. Aebersold, J. Leavitt, R. A. Saavedra, L. E. Hood, S. B. Kent, Proc. Natl. Acad. Sci. U.S.A. 84, 6970 (1987).

33. We thank D. Haque for expert technical assistance and J. Donaldson, J. Bonifacino, A. Dancis, T. Rouault, S. Lee, J. Humphrey, and J. Gnarra for critical reading of the manuscript. Supported by the William K. Warren Foundation (D.R.D.); by the Howard Hughes Medical Institute-NIH Research Scholars Program (D.Y.T.C.); and by NIH grant GM41628 and by funds provided to the Oklahoma Medical Research Foundation by the H.A. and Mary K. Chapman Charitable Trust (T.A., P.G., R.C.C., and J.W.C.).

18 July 1995; accepted 15 August 1995 